\title{
The influence of market heterogeneity on customer loyalty: A multigroup analysis.
}

Completed Research Paper

\author{
Araceli Picón-Berjoyo \\ University of Seville \\ araceli@us.es \\ Ignacio Castro \\ University of Seville \\ icastro@us.es
}

\author{
Carolina Ruiz-Moreno \\ University of Seville \\ carolruiz@us.es
}

\begin{abstract}
Loyalty is configured as one of the main determinants of firm performance. Many works have proposed models that analyze the relationship between loyalty and its main determinants: the customer perceived value (PV), their level of satisfaction and their perceived switching costs (PSC). Thus, the aim of this study is to validate a model that gathers the relationships between these variables and analyze the influence of customer characteristics - propensity towards switching and customer involvement- on these relationships in the insurance industry. The results show that (a) for the whole sample, perceived value, satisfactions and switching costs are set as antecedents of loyalty; (b) however, for customers with high tendency to switch, the path to a loyalty behavior is only mediated by the influence of their perceived value in their satisfaction; and finally (c) for these individuals, the strength of the relationship between satisfaction and loyalty is lower than customers with low tendency to switch.
\end{abstract}

Keywords: Customer perceived value, Customer satisfaction, Perceived switching costs, Loyalty, Market heterogeneity, Partial least squares.

\section{Introduction}

The relation between customer value and loyalty remains one of the most fruitful research lines in the area of marketing (Flint, Blocker and Boutin, 2011). The high level of interest in this relation for academics and business managers stems from its implications for the firm's profitability. Few works, however, have analysed the efficiency of value creation strategy for an organisation (Sánchez-Fernández et al., 2013).

Most works on loyalty show its financial consequences for the firm. Likewise, there have been numerous works which have centred on analysing the factors or antecedents which determine loyalty, as well as the mechanisms that enable the identifying of customer profiles which are susceptible of being loyal. These facilitate the development of the appropriate strategies to act in the market (Roos and Gustafsson, 2007). Thus, the literature has highlighted three clear antecedents of customer loyalty: the customer perceived value (PV), their degree of satisfaction, and the existence of switching costs (Yang and Peterson, 2004; Flint, Blocker and Boutin, 2011). Any study on the triggers of loyalty must take into account that the PV of a service received will determine the customer's propensity to maintain a lasting relation with the supplier and, therefore, their loyalty. This may be directly or through their satisfaction or the existence of perceived switching costs (PSC). This means a direct or indirect effect on their loyalty (Lam et al, 2004). The literature underscores that both ways are 
able to act on customer loyalty and there are works which have tried to settle which of these options is most effective. It has been agreed that it is necessary for both variables to be present in business strategies. Centring uniquely on creating PSC can cause difficulties for the customer when purchasing the product or service or be neutralised by competitors' actions (Burnham et al., 2003). On the other hand, mere satisfaction itself is not enough (Oliver, 1999). Nevertheless, in spite of this fruitful research line, it is true that the empirical results achieved have not been as conclusive as expected. This is why some research remarks that to give an answer to this puzzle an additional variable must be taken into account: market heterogeneity. Some authors propose the importance of studying the differences between consumers due to their heterogeneous behaviour patterns (Floh et al., 2014). Hence, differences at the demographic, socioeconomic and psychographic level between customers influence their expectations and behaviours (Mittal and Kamakura, 2001; Castro et al., 2007).

We propose a double research aim in this context. On the one hand, we set out a theoretical model which helps to explain the main determinants of loyalty and their relations in the services area. On the other hand, having presented the model, we mean to explain the influence of the customers' psychographic characteristics, specifically their level of involvement with the service and their degree of propensity towards switching. That is to say, we will aim to demonstrate the influence that heterogeneity has on generating customer loyalty and its determinant variables.

To achieve these objectives, we first carry out a theoretical review of the concept of market heterogeneity and the determinants of customer loyalty. This will give rise to the formulating of the research hypotheses and the design of the conceptual model which is the aim of the study. After, the empirical study carried out in the Spanish insurance sector and the methodology developed is shown, with particular emphasis on latent segmentation and multigroup analysis. Finally, we present the discussion of the main results and conclusions.

\section{Conceptual Framework}

\subsection{Customer loyalty: determinant factors.}

The degree of loyalty developed by customers indicates their probability of remaining in a relation with a company in the future. To determine the direction of this behaviour, it is essential to know which its triggers are, as, according to their origin, customers can be identified with greater of lesser possibilities of continuing the relationship in the long term (Roos and Gustafsson, 2007). Likewise, it is necessary to differentiate the approaches via which loyalty is analysed. The literature has given more relevance to behavioral and attitudinal approaches. Thus, behavioral loyalty refers to the degree to which a customer shows a repeated purchasing behavior towards a service provider (Gremler et al., 2001). Affective loyalty implies a desire to maintain a relationship on the basis of a generally positive feeling towards established ties and purchasing experience (Oliver, 1999).

The services literature indicates that firms will only achieve true loyalty in their customers through the delivery of a higher value. Many works have aimed to propose the direct or indirect relation between these variables. These studies consider that firms seeking customer loyalty must not centre exclusively on the creating, activating and maintaining of switching barriers, but rather loyalty must be built on the delivery of a higher value for the customer (Lam et al., 2004; Yang and Peterson, 2004). In this way, PV refers to the customer's judgment of the proposal's perceived value. This judgment is based on the perceptions that the customer has in relation with the benefits which are obtained from the product, service or relation with the supplier firm (in terms of quality, image, etc.), as well as the sacrifices which must be made to acquire them (in terms of money, time and effort). Moreover, the literature 
points out that this valuation is carried out compared with the rest of the competing offers (Woodall, 2003).

Nonetheless, the PV cannot be considered as an ultimate aim for organisations, but rather those results or consequences which can stem from it. The role of loyalty is to be highlighted, given its influence on firms' results. Thus, some authors indicate that loyalty generates higher financial results as it enables not only an increase in income - increase in sales, in references, etc.- but also reduces costs - less marketing effort, a lower number of returns, etc. (McNaughton et al., 2001).

All of this leads us to propose PV as our model's starting point. Furthermore, although there are works which set out a direct relation between value and loyalty (i.e., Floh et al. 2015), in our work we have opted for considering the role of satisfaction and PSC as mediator variables in the relation between customer value and loyalty. This means considering two ways: one with positive connotations related to satisfaction and generating benefits and relational links, and another that is negative and connected with those factors which hinder the switching process to a new supplier.

Satisfaction is considered as "the degree of overall pleasure or contentment felt by the customer, resulting from the ability of the service to fulfil the customer's desires, expectations and needs in relation to the service" (Hellier et al, 2003). The relation between PV and satisfaction has been widely dealt with, finding a positively and direct relation between both variables (Yang and Peterson, 2004).

On the other hand, customer satisfaction can be examined from a transactional perspective. That is, the evaluation which stems from a specific service encounter or the experiences generated throughout the different service encounters or episodes which make up the relationship, called "global satisfaction with the service". Indeed, most research suggests that this global or accumulated satisfaction is what turns out to be most relevant in determining customer loyalty (Olsen and Johnson, 2003). The literature indicates the positive influence of satisfaction on the level of affective loyalty (Beerli et al., 2004) and on the level of future behavioral intentions loyalty (Beerli et al, 2004). Yet, loyalty is not the same for all its dimensions: the relation between satisfaction and affective loyalty has a greater strength.

Switching costs are defined as "those costs which are associated with moving from one supplier to another" (Porter, 1980). In general, they mean monetary, psychological and time losses for the customer (Bitner, 1995) which are connected with both abandoning the current relationship and starting up a new relationship with an alternative supplier. Through the creation of PSC, firms can discourage customers from attempting to abandon the relationship, and increase the difficulties that the switching procedure entails. The recent literature recognises that PSC is a multidimensional construct (Barroso and Picón, 2012). Therefore, the nature of these costs (relational, monetary, psychological, or associated with the time the switching process takes up) can be very different depending on the sector or industry.

Most contributions link the concept of PSC to customer loyalty and to supplier switching behaviour (Hellier et al., 2003; Picón et al., 2014). All of them point out that PSC encourage loyalty, hindering the change to another supplier even when the satisfaction level is low.

Based on these arguments, we propose the theoretical model shown in Figure 1.

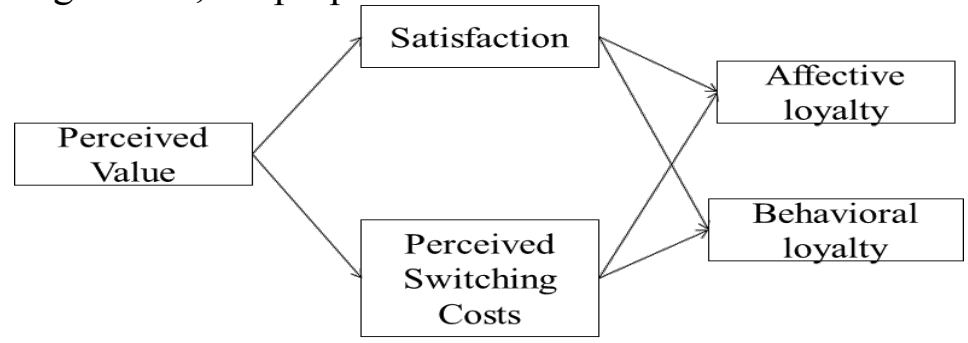

Figure 1: Theoretical model 


\subsection{Market heterogeneity}

The literature shows that customers who have different personal characteristics also show differences in their future behaviour, despite having similar levels of satisfaction with their suppliers (Mittal and Kamakura, 2001). Moreover, the effect of satisfaction, PV and PSC on the intention of future behaviour is contextual, varying in function of the individuals' psychographic characteristics (Ganesh et. al., 2000; Keaveney and Parthasarathy, 2001).

The heterogeneity of customers is reflected in the concept of segmentation. This is generally based on demographic, socioeconomic and psychographic characteristics. Research has identified certain segmentation variables which can be linked to the PV, customer satisfaction and future behavior loyalty (Ruiz et al., 2007). However, there is limited empirical evidence which endorses the notion that customer heterogeneity affects the nature of relationships between suppliers and customers (Castro et al., 2007). Of all the possible characteristics to identify customer profiles, we have opted for analysing the level of the customer's involvement with the service and the propensity towards switching as segmentation criteria.

The first variable refers to the personal relevance (both cognitive and affective) which people attribute to a decision about the basis of their fundamental values, aims and personality (Bienstock and Stafford, 2006). A greater degree of involvement and commitment to a relationship is associated with a greater resistance to changing beliefs (Keaveney and Parthasarathy, 2001). Furthermore, the level of satisfaction attained with the service and the customer's PSC may increase the degree of involvement and therefore the resistance to abandoning the relationship (Young and Denize, 1995).

Also, a greater degree of customer involvement enables strong links to exist between the parties (Jones et al., 2002). This favours the VP, attaining a specific degree of satisfaction with the relationship, hence motivating the customer's desire to avoid change (Varki and Wong, 2003). On the other hand, thoroughly committed customers are more inclined to attribute a considerable risk and uncertainty to a possible change (Bienstock and Stafford, 2006; Keaveney and Parthasarathy, 2001) and will therefore tend to be more loyal.

Customers with a thorough propensity towards switching are "anxious for change" (Ganesh et al., 2000) and could therefore begin a switching process without any apparent motive. These customers really enjoy seeking alternative information and suppliers, as they look for stimulation via investigating new experiences and the pleasure of trying out new suppliers and brands (Vázquez and Foxall, 2006).

An individual's propensity towards switching is to be found in a continuum. Thus, at one extreme of the continuum are those who have a lesser degree of propensity towards switching, qualified as "risk adverse", with a low tendency to carry out risky actions. However, this does not mean that the customers will always stay with the same supplier or the same product/service, as this will depend on the category of the product/service, of other personal or situational characteristics and on other variables such as the PV and satisfaction with the service. At the opposite end of the continuum are those individuals who have a high propensity towards switching, who have experience in the supplier switching process and who are also "daring" and, therefore, tend to take risky decisions regardless of their consequences.

As a result of these arguments we present the following hypotheses:

H1: The intensity of the relationship between the PV and customer satisfaction is moderated by the customer's propensity towards switching and the customer involvement.

H2: The intensity of the relationship between the PV and PSC is moderated by the customer's propensity towards switching and the customer involvement.

H3: The intensity of the relationship between customer satisfaction and affective loyalty is moderated by the customer's propensity towards switching and the customer involvement. 
H4: The intensity of the relationship between customer satisfaction and behavioral loyalty is moderated by the customer's propensity towards switching and the customer involvement.

H5: The intensity of the relationship between PSC and affective loyalty is moderated by the customer's propensity towards switching and the customer involvement.

H6: The intensity of the relationship between PSC and behavioral loyalty is moderated by the customer's propensity towards switching and the customer involvement.

\section{Research Methodology}

\subsection{Sample and data collection}

This study analyses firms in the Spanish insurance sector. The sector is made up of insurance companies, mutual insurance companies and banks which offer different types of insurance, including those which offer these services electronically and online firms. The information comes from 786 customers of 74 companies $(83.94 \%$ of the total volume of premiums in the Spanish insurance sector). All of these companies offer different types of insurance policies and do not operate from a specific location within Spain. The data come from personal interviews and an online survey (via a website). The interviews take place in the branch offices of the companies. An online survey allows customers to answer the questionnaire directly, increasing the survey's penetration, to reach customers who do not frequent company offices. Deploying a snowball sampling technique, potential respondents (colleagues and acquaintances) receive email invitations containing the embedded URL to the website hosting the survey. Nevertheless, we took into account the possibility of differences in the answers, and the results did not show significant differences.

The diversity of services selected with different characteristics between them, and the fact that the majority $(56.5 \%)$ of respondents have at least a five-year commercial relationship with their insurance company, facilitated the obtaining of heterogeneous perceptions regarding the variables analysed.

\subsection{Measurement instruments}

The operationalisation of the PSC variable entails an adaptation of Burnham et al.'s (2003) instrument. The PSC variable is as an aggregate multidimensional construct (reflective firstorder, formative second-order) with six reflective first-order dimensions, as has been described in previous works (Barroso and Picón, 2012). Regarding the scales related to the rest of the constructs analysed in the study, we use the scale developed by Maloles (1997) to measure the level of customers' satisfaction with their usual insurance company. With respect to the PV, we opted for a unidimensional measurement scale (Martín et al., 2004), as the aim of this work is to obtain a global valuation by the customer and analyse its relation to other constructs. Concerning customer loyalty, we selected the scales developed by Gremler et al. (2001). Lastly, with respect to the variables used to measure market heterogeneity, in the case of the customer involvement level we used a scale adapted from the works of Varki and Wong (2003). To measure the degree of propensity towards switching, the scale proposed by Antón and Rodríguez (2004) was employed.

\subsection{Data analysis}

Given that an insurance company's purchase process and customer behaviour are determined by the customers' psychological characteristics, it would not be realistic to put forward a sole model which would fit all decision making. In this sense, latent segmentation 
proposes seeking subgroups of elements with a certain number of variables. This generates segments within the general population.

In our case, to attain the first aim of this research, we carried out the market segmentation based on the customers' involvement level with the service and their degree of propensity towards switching. This was carried out via a latent class cluster analysis (Wedel and Kamakura, 2000; Castro et. al. 2007). Latent class segmentation enables the identifying of groups of consumers with similar behaviours. This analysis includes a latent variable (Kcategory) and each category represents a different cluster. It is used to assign customers who have the probability of this element belonging to a segment or latent class. Latent Gold 4.0 was the software used.

This technique provides the optimum number of clusters into which the market must be divided. The criterion employed to identify this number is the least value of the BIC indicator (Bayesian Information Criteria).

To achieve the second aim of our work and to test the possible differences of the model proposed in each of the groups resulting from the latent class analysis, we carried out a multigroup comparison approach with the use of PLS (Smart PLS 3.1.9 software was usedRingle and Wende, 2014). We estimated the path coefficients for the total sample and for each group or subsample (Sarstedt et al., 2011). Finally, we analysed the differences between the coefficients' paths. To determine the significance of differences between the estimated parameters for each of the groups we have followed the parametric approach, considering both equal variances and different variances (Chin, 2010).

\section{Analysis of Results}

\subsection{Results of market heterogeneity.}

For the latent class clusters segmentation it is necessary to identify the number of segments through a statistical criterion, in this case the BIC indicator. The results suggested that, based on the two variables which determine the customers' behaviour, 3 latent segments of customers can be identified, as this solution represented the BIC of least value. Tables 1 and 2 show the description of the clusters based on the variables chosen for the segmenting, demonstrating the profiles and the sizes of these clusters. The Wald test enables us to evaluate if there is a statistically significant association between the exogenous variables and the segments identified. As can be seen in Table 1, all the variables used as a segmentation criterion are significantly different in the three clusters (according to the p-values of the Wald test). That is to say, they have discriminating power between the segments. The $\mathrm{R}^{2}$ values indicate the variance which each variable explains in the model.

Table 1: Parameters of the clusters

\begin{tabular}{lcccccc}
\hline & Cluster 1 & Cluster 2 & Cluster 3 & Wald & p-value & $\mathbf{R}^{2}$ \\
\hline Customer involvement & 1.3118 & -1.0837 & -0.2281 & 1210.5562 & $1.40 \mathrm{E}-263$ & 0.6956 \\
Propensity towards switching & -0.3847 & 0.2406 & 0.1441 & 38.3163 & $4.80 \mathrm{E}-09$ & 0.0604 \\
\hline
\end{tabular}

Table 2: Size of the clusters and profiles

\begin{tabular}{lccc}
\hline & Cluster 1 & Cluster 2 & Cluster 3 \\
\hline Size & 0.3231 & 0.3396 & 0.3371 \\
Mean Customer involvement & 3.3955 & 1 & 1.8556 \\
Mean Propensity towards switching & 4.6555 & 5.2808 & 5.1843 \\
\hline
\end{tabular}

Therefore, the results show how the market can be divided into three segments based on the behaviour of the customers (defined by their level of involvement with the service and their degree of propensity towards switching). We can see how the three clusters have a 
similar size (Table 2): $32.31 \%$ of the respondents (254) are in cluster 1, 33.96\% (267) are in cluster 2 and $33.71 \%$ (265) are in cluster 3, which encompasses those customers with a mean position in the two variables analysed. In the first cluster are included the people in the sample with the greatest level of involvement and the least value of propensity towards switching, which is why they have a lower tendency to switch their service supplier: "customers with a low tendency to switch". The second cluster contains those customers with a very low level of involvement and who, on the contrary, have the highest propensity towards switching. This is, then, those customers with the greatest tendency to switch their insurance company: "customers with a high tendency to switch".

After identifying the clusters, a multigroup analysis was carried out to check if there were significant differences between them with respect to the model proposed. For this analysis we used the two clusters which are the extreme positions. That is, clusters 1 made up of those customers with a low tendency to switching and cluster 2 with those who have a high tendency to switching. For this second analysis the total sample was 521 customers.

\subsection{Measurement and structural model.}

In our work, we have modeled the conceptual variables as composite factor. Thus, we have chosen a composite model in which it has drawn a reflective design where the different indicators are different aspects but they exhibit a certain correlation. First we carried out an analysis of the measurement model for the total sample in which the individual reliability of each item, the reliability of the constructs, the variance extracted (AVE) and the discriminant validity was analysed. The results, in the case of the reflective constructs, showed a higher composite reliability and AVE than the values recommended and exhibit discriminant validity (Roldán and Sánchez Franco, 2012). The evaluation of formative measurement models (PSC) at the indicator level tests for potential multicollinearity between items and analyses weights (Henseler et al., 2009). The maximum variance inflation factor (VIF) value for the aggregate multidimensional construct is 2.12 , well below the threshold of 3.3.

Likewise, the results of the measurement model for each of the subsamples were also found to be valid according to the commonly accepted guidelines (Hair et al., 2013). Due to this we can state that the measurement model proposed does not vary when customer heterogeneity is taken into account. That is, factor loadings for the same indicators are equivalent between customers with a low or high tendency to switch, hence guaranteeing the metric invariance. In Table 3 we can observe that the great majority of the factorial loadings for the same item are invariant in both subsamples - only $2 / 27$ indicators turn out to be significantly different in both samples. We can, then, assume the metric invariance of the model proposed.

Table 4 shows the results of the structural model assessment. Consistent with Hair et al. (2013), bootstrapping (5000 resamples; one-tailed Student t distribution with (n-1) degrees of freedom) was used to generate standard errors, t-statistics, and percentile $95 \%$ confidence intervals. This analysis was carried out both for the total sample and for the two subsamples. Five of the main paths are significant, except for the PSC relation and future behavioral intentions loyalty in the total sample and in the subsample which has customers with a high tendency to switch suppliers. The endogenous constructs achieve $\mathrm{R}^{2}$ values between 0.482 and 0.56 for affective loyalty and between 0.277 and 0.49 for behavioral loyalty. These values are considered to be moderate (Chin, 2010). The predictive relevance of the theoretical/structural model is assessed with the cross-validated redundancy index $\left(\mathrm{Q}^{2}\right)$ for endogenous constructs. Since all $\mathrm{Q}^{2}$ values are greater than 0 , we found evidence that our model has predictive relevance (Chin, 2010). Finally, we report the SRMR composite factor model in order to determine to what extent the model fits the data. In our three models this 
indicator is above 0.08 so the good fit of the models is confirmed (SRMR total sample $=$ 0.042; SRMR low tendency $=0.052$; SRMR high tendency $=0.058)($ Henseler et al., 2014).

Table 3: Metric invariance assessment multigroup analysis

\begin{tabular}{|c|c|c|c|c|c|c|c|}
\hline $\begin{array}{l}\text { Construct/ } \\
\text { Indicators }\end{array}$ & $\begin{array}{c}\text { Diff } \\
\text { (High-Low) }\end{array}$ & $\begin{array}{l}\text { Parametric } \\
\text { Test t-value }\end{array}$ & $\begin{array}{c}\text { Welch } \\
\text { Satterthwait }\end{array}$ & $\begin{array}{l}\text { Construct/ } \\
\text { Indicators }\end{array}$ & $\begin{array}{c}\text { Dif } \\
\text { (High-Low) }\end{array}$ & $\begin{array}{l}\text { Parametric } \\
\text { Test t-value }\end{array}$ & $\begin{array}{c}\text { Welch } \\
\text { Satterthwait }\end{array}$ \\
\hline SAT & \multicolumn{7}{|c|}{ PV } \\
\hline S1 & 0.031 & 0.836 & 0.825 & VP1. & 0.081 & $1.916^{*}$ & 1.933 \\
\hline S2. & 0.008 & 0.210 & 0.210 & VP2. & 0.021 & 0.800 & 0.803 \\
\hline S3. & 0.024 & 0.655 & 0.652 & VP3. & 0.052 & 0.813 & 0.804 \\
\hline S4. & 0.420 & 1.625 & 1.665 & VP4. & 0.025 & 0.527 & 0.530 \\
\hline S5. & 0.000 & 0.007 & 0.007 & VP5. & 0.021 & 0.643 & 0.636 \\
\hline S6. & 0.009 & 0.365 & 0.367 & VP6. & 0.056 & 0.804 & 0.796 \\
\hline S7. & 0.007 & 0.213 & 0.213 & VP7. & 0.023 & 0.685 & 0.689 \\
\hline PSC & & & & VP8. & 0.041 & 1.011 & 0.995 \\
\hline EC. & 0.160 & 1.136 & 1.138 & VP9. & 0.115 & $2.265^{*}$ & $2.305^{*}$ \\
\hline SC. & 0.034 & 0.312 & 0.309 & AFFEC_LOYAL & & & \\
\hline BC. & 0.005 & 0.087 & 0.086 & $\overline{\mathrm{AL} 1 .}$ & 0.028 & 0.712 & 0.720 \\
\hline $\mathrm{MC}$ & 0.013 & 0.116 & 0.116 & AL2. & 0.063 & 1.493 & 1.468 \\
\hline PR & 0.078 & 0.963 & 0.957 & AL3I. & 0.012 & 0.419 & 0.416 \\
\hline \multirow[t]{3}{*}{ ER } & 0.016 & 0.270 & 0.26 & BEHAV_LOYAL & & & \\
\hline & & & & FBI1. & 0.562 & 1.505 & 1.543 \\
\hline & & & & FBI2. & 0.026 & 0.485 & 0.495 \\
\hline
\end{tabular}

Table 4: Direct and indirect effects. Bias-correct $95 \%$ confidence intervals and indirect effect multigroup comparison results

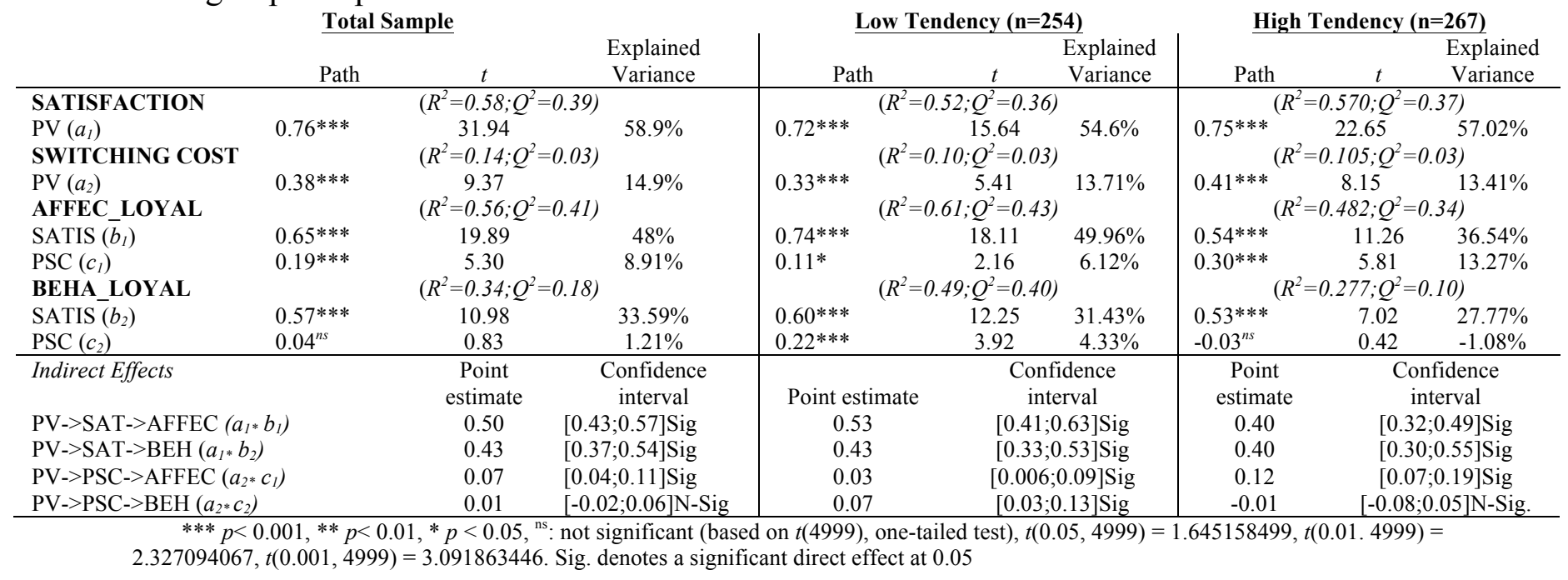

In addition, Table 4 shows the amount of variance that each antecedent variable explains on each dependent variable, achieving the greatest value in the case of the PV variable when explaining the explained variance of satisfaction $(58.9 \%)$ and in the case of satisfaction variable when explaining the explained variance of the affective loyalty (48\%). In fact, we analyse the percentage of explained variance of loyalty both total simple and sub-samples, the satisfaction level is the main determinant, which is largely influenced by its PV. Also, Table 4 reflects that three of the four indirect effects being significant for the whole simple and the subsamples, generating significant differences according to the customer tendency to switch, in the effect which PV causes on behavioral loyalty through PSC. Therefore, in those customers with low tendency of switching providers PV is an important factor that strengthening their affective and behavioral loyalty, through their influence on satisfaction and PSC. However, if the tendency of switching providers is high, PV does not influence on behavioral intentions loyalty via PSC, but if it did by satisfaction.

Once the metric invariance has been guaranteed in the measurement model and we have 
tested the structural model, we carry out the multi-group analyses to allow the testing of the moderating role of customer heterogeneity, considering the high or low customer tendency to switch, on the relationships included in our research model. Due to the exploratory character of our study, we have applied the parametric approach. The moderating effect is examined using a t-test with pooled standard errors. This approach requires the data to be distributed normally and/or the variances of the two samples being not too different from one another tparametric (EV)-. In the case of our assuming different variances for the two samples, a Welch-Satterthwait test -tparametric(NEV)-can be applied (Sarstedt et al., 2011). We have applied both tests in our comparison obtaining similar results (Table 5). As we can observe, we find statistical support for $\mathrm{H}_{3}, \mathrm{H}_{5}$ and $\mathrm{H}_{6}$.

Table 5: Multigroup comparison test results

\begin{tabular}{lcccc}
\hline \multicolumn{1}{c}{ Relationships } & Diff(High-Low) & $\mathrm{t}_{\text {parametric }}(\mathrm{EV})$ & $\mathrm{t}_{\text {parametric }}(\mathrm{NEV})$ & Significance \\
\hline $\mathrm{H}_{1}:$ PV->SAT & 0.032 & 0.567 & 0.563 & No \\
$\mathrm{H}_{2}:$ PV->PSC & 0.083 & 1.067 & 1.063 & No \\
$\mathrm{H}_{3}:$ SAT->AFFEC & 0.202 & $3.127^{* * *}$ & $3.145^{* * *}$ & Yes \\
$\mathrm{H}_{4}:$ SAT->BEH & 0.070 & 0.765 & 0.773 & No \\
$\mathrm{H}_{5}:$ PSC->AFFEC & 0.195 & $2.604^{* *}$ & $2.609^{* *}$ & Yes \\
$\mathrm{H}_{6}:$ PSC->BEH & 0.260 & $2.529^{* *}$ & $2.555^{* *}$ & Yes \\
\hline \multicolumn{1}{c}{ Note: $* *$ significant at 0.05 (two-tail t distribution, one-sided test); $*$ significant at 0.01 (two-tail t distribution, one-sided test); ns $=$ not significance }
\end{tabular}

In summary, the results support the reliability and validity of the measurement model, both in the total sample and in the sub-samples. Moreover, we test the metric invariance of our proposed model, because the measurement model does not vary when the original sample is dividing into two subsamples (Table 3). These results support the universal validity of the constructs: PV, Satisfaction and PSC, main pillars that customer loyalty is based.

The findings of the structural model also support the validity of the relationships between satisfaction and PSC constructs with affective loyalty for all individuals, which have been widely tested in the literature. Nevertheless, the results in Table 5 show significant differences between these two groups for the relationship between PSC and affective loyalty, being this latter stronger in the case of customers with high tendency to switch providers. Moreover, firms must take into account the customer heterogeneity when designing loyalty strategies, so for customers with high tendency to switch, creating switching barriers will not prevent a future change of provider. So, a significant relationship between PSC and future behavioral intentions loyalty in this group was not found (table 4). Analysis of the indirect effects also shows that PV influences on affective and behavioral loyalty differently in the two groups. Thus, on the one hand, customers with a low tendency to switch, the influence is achieved through satisfaction and PSC; and on the other hand, in customers with a high tendency to switch the behavioral intentions loyalty is achieved only by satisfaction. Furthermore, the results in Table 5 show significant differences between these two groups for the relationship between satisfaction and affective loyalty, being this latter stronger in the case of customers with low tendency to switch providers.

\section{Conclusions}

In the present study we have been able to test the existence of heterogeneity in the Spanish insurance market regarding the customers' psychographic characteristics and how these generate different behaviours related to their degree of loyalty. The two variables chosen -the level of involvement of the customers with the service and their degree of propensity towards switching their insurance company - has enabled us to carry out a segmentation of the sample into two principal groups of different customers: a group with "individuals with a low tendency to switch", and a second group with "individuals with a high tendency to switch".

Regardless of the characteristics of the customers, the insurance companies must seek 
their loyalty, based on the provision and development of a value which the customers perceive as superior. This perception of a superior value than the competition will generate a greater tendency towards the customers' loyalty through two ways: bringing about a feeling of satisfaction in the customer and building switching barriers. Both factors are going to make the customers maintain their relationship with the firm over time. Indeed, these results obtained in the insurance sector are consistent with those of other research works and sectors (Yang and Peterson, 2004; Sánchez-Fernández et al., 2013).

However, if we consider the characteristics of the customers, some important differences are found related to the determinants of loyalty. The most significant differences are in the relation between PSC and behavioral loyalty for those customers with a high tendency to switch (cluster 2). This group of customers bases its loyalty behavior on the degree of satisfaction and the PV of the firm's offer. These customers will require retention strategies which influence these factors in a positive domain, based on elements such as the service quality, the price and the improvement of the firm's image. For these customers, building switching barriers will not turn out to be so relevant, due perhaps to their high predisposition towards switching. This means that, even perceiving high switching costs, their degree of loyalty to the firm is maintained or even decreased based on their perception of the service.

Furthermore, we have also tested the existence of a difference between both segments regarding the strength of the relationship between satisfaction and PSC with affective loyalty. In the case of satisfaction-affective loyalty link, this relation is stronger for customers with a low tendency to switch. These are individuals for whom economic or social risks are not crucial to maintain a relationship with a provider in time. This may be due either to their personality traits or to the importance that they give to the service, which makes them be little involved with it. The main way to build loyalty in these individuals is to improve the service in order to increase consumer perception. In the case of PSC-affective loyalty link, customers with a high tendency to switch may experience positive feelings of the service provider, although they have the intention to switch in the future because other reasons such as monetary cost of service.

Moreover, we can say that for those individuals with low tendency to switch (cluster 1), loyalty strategies must be based not only on satisfaction but also on generating negative switching barriers (hindering the seeking of other suppliers and the beginning of a new relationship, etc.) or positive switching barriers (generating social or economic benefits, links, and so on). Nonetheless, raising PSC, especially those which are called negative, may be a dangerous strategy for firms, as they can retain customers against their will, reducing their level of satisfaction and making them feel attracted by the offers of competitors, in whom they perceive that they may obtain a better quality/price relationship or a better or more varied service, cover, etc.

Finally, the fact that they were able to test the influence of customer characteristics in other relationships, mainly those that support the role of PV on generating loyalty, reinforces the validity of this model for the insurance industry. In fact, it is a model that has been validated in other works and industries and therefore with a strong support from the literature. Thus, we have tested that the differences that involves consideration of the customer characteristics does not invalidate the model, but if it allows us to understand better how to retain customers in this industry in a sustainable manner over time.

The main limitation is not including other variables relative to the characteristics of the customer as the degree of attractiveness of alternatives available in the market (Capraro et.al, 2003), the previous experiences with supplier switching (Burnham et al., 2003) and the length of the relationship (Jones et al., 2002). Including these variables would enable us to go more thoroughly into the differences in the relations between the antecedents of loyalty for different groups of customers. 


\section{References}

Antón, C., \& Rodríguez, A.I. (2004). Formas de lealtad a la marca: identificación empírica y determinación de sus principales características. Cuadernos de Economía y Dirección de Empresas, 18, 122-145.

Barroso, C., \& Picón, A. (2012). Multi-dimensional analysis of perceived switching costs. Industrial Marketing Management, 41, 531- 543.

Beerli, A., Martín, J., \& Quintana, A. (2004). A model of customer loyalty in the retail banking market. European Journal of Marketing, 38, 253-275.

Bienstock, C., \& Stafford, M. (2006). Measuring involvement with the service: a further investigation of scale validity and dimensionality. Journal of Marketing Theory and Practice, 14, 209-221.

Bitner, M.J. (1995). Building service relationships: it's all about promises. Journal of the Academy of Marketing Science, 23, 246-251.

Castro, C.B., Martin, E.A., \& Martin, D.R. (2007). The influence of market heterogeneity on the relationship between a destination's image and tourists' future behaviour. Tourism Management, 28, 175-187.

Chin, W.W. (2010). How to write up and report PLS analyses. In Esposito Vinzi, V., Chin, W. W., Henseler, J., \& Wang, H. (Eds.) Handbook of partial least squares: Concepts, methods and applications (pp. 655-690). Berlin, Germany: Springer-Verlag.

Flint, D.J., Blocker, C.P., \& Boutin, P.J. (2011). Customer value anticipation, customer satisfaction and loyalty: An empirical examination. Industrial Marketing Management, 40, 219-230.

Floh, A., Zauner, A., Koller, M., \& Rusch, T. 2014. Customer segmentation using unobserved heterogeneity in the perceived-value-loyalty-intentions link. Journal of Business Research, 67, 974-982.

Ganesh, J., Arnold, M.J., \& Reynolds, K.E. (2000). Understanding the customer base of service providers: an examination of the difference between switchers and stayers. Journal of Marketing, 64 (July), 65-87.

Gremler, D., Brown, S., Bitner, M.J., \& Parasuraman, A. (2001). Customer Loyalty and Satisfaction: What Resonates in Service Context? Working Paper. Bowling Green State University.

Hair Jr, J. F., Hult, G. T. M., Ringle, C., \& Sarstedt, M. (2013). A primer on partial least squares structural equation modeling (PLS-SEM). Sage Publications.

Hellier, P., Geursen, G., Carr, R., \& Rickard, J. (2003). Customer repurchase intention. A general structural equation model. European Journal of Marketing, 37, 1762-1800.

Henseler, J., Ringle, C. M., \& Sinkovics, R. R. (2009). The use of partial least squares path modeling in international marketing. Advances in International Marketing, 20, 277320.

Henseler, J., Dijkstra, T., Sarstedt, M., Ringle, C.M., Diamantopoulos, A., Straub, D.W., Ketchen, D. J. Jr., Hair, J.F., Hult, G.T., \& Calantone, R.J. (2014). Common beliefs and reality about PLS: Comments on Rönkkö \& Evermann (2013). Organizational Research Methods, 17, (2), 182-209.

Jones, M., Mothersbaugh, D., \& Beatty, S. (2002). Why customers stay: measuring the underlying dimensions of services switching costs and managing their differential strategic outcomes. Journal of Business Research, 55, 441-450.

Keaveney, S., \& Parathasarathy, M. (2001). Customer switching behavior in online services: an exploratory study of the role of selected attitudinal, behavioral, and demographic factors. Journal of the Academy of Marketing Science, 29 (4), 374-390.

Lam, S.Y., Shankar, V., Erramilli, M. K., \& Murthy, B. (2004). Customer Value, Satisfaction, 
Loyalty, and Switching Costs: An Illustration From a Business-to- Business Service Context. Journal of the Academy of Marketing Science, 32 (3), 293-311.

Maloles, C.M. (1997). The Determinants of Customer Retention. Doctoral Thesis. The City of University of New York.

Martín, D., Barroso, C., \& Martín, E. (2004). El Valor Percibido de un Servicio. Revista Española de Investigación de Marketing ESIC, 8 (1), 47-73.

McNaughton, R.B., Osborne, P., Morgan, R.E., \& Kutwaroo, G. (2001). Market Orientation and Firm Value. Journal of Marketing Management, 17, 521-542.

Mittal, V., \& Kamakura, W.A. (2001). Satisfaction, Repurchase Intent, and Repurchase Behaviour: Investigating the Moderating Effect of Customer Characteristics. Journal of Marketing Research, 38 (1), 131-142.

Oliver, R. (1999). Whence consumer loyalty? Journal of Marketing, 63, 33 - 44.

Olsen, L. \& Johnson, M. (2003). Service Equity, Satisfaction, and Loyalty: From TransactionSpecific to Cumulative Evaluations. Journal of Service Research, 5 (3), 184-195.

Picón, A., Castro, I., \& Roldán, J.L. (2014). The relationship between satisfaction and loyalty: a mediator analysis. Journal of Business Research, 67, 746-751.

Porter, M. (1980). Competitive strategy, Techniques for analyzing industries and competitors. Macmillan, New York.

Ringle, C.M. \& Wendel (2014), S. SmartPLS 3.0 (version 3.1.9). Beta. Hamburg.

Roldán, J. L., \& Sánchez-Franco, M. J. (2012). Variance-Based Structural Equation Modeling: Guidelines for Using Partial Least Squares. Research methodologies, innovations and philosophies in software systems engineering and information systems, 193.

Roos, I., \& Gustafsson, A. (2007). Understanding Frequent Switching Patterns. A Crucial Element in Managing Customer Relationships. Journal of Service Research, 10 (1), 93-108.

Ruiz, D.M., Barroso, C.M., \& Martín, E.A. (2007). Explaining Market Heterogeneity in Terms of Value Perceptions. Service Industries Journal, 27, 1087-1110.

Sánchez-Fernandez, R., Swinnen, G., \& Iniesta-Bonillo, M.A. (2013). La creación de valor en servicios: una aproximación a las dimensiones utilitarista y hedonista en el ámbito de la restauración. Cuadernos de Economía y Dirección de la Empresa, 16, 83-94.

Sarstedt, M., Henseler, J., \& Ringle, C. M. (2011). Multigroup analysis in partial least squares (PLS) path modeling: Alternative methods and empirical results. Advances in International Marketing, 22(1), 195-218.

Yang, Z., \& Peterson, R.T. (2004). Customer perceived value, satisfaction, and loyalty: The role of switching costs. Psychology and Marketing, 21, 799-822.

Young, L., \& Denize, S. (1995). A concept of commitment: alternative views of relational continuity in business service relationships. Journal of Business \& Industrial Marketing, 10 (5), 22-37.

Varki, S., \& Wong, S. (2003). Consumer involvement in relationship marketing of services. Journal of Service Research, 6, 83-91.

Vázquez, R., \& Foxall, G. (2006). Positive vs. negative switching barriers: the influence of service consumers' need for variety. Journal of Consumer Behavior, 5, 367-379.

Wang, Y., Lo, H.P., Chi, R., \& Yang, Y. (2004). An integrated framework for customerrelationship-management performance: a customer based perspective from China. Managing Service Quality, 14, 169-182.

Wedel, M., \& Kamakura, W. (2000). Market segmentation: Conceptual and methodological foundations. Boston, EUA: Kluwer Academic.

Woodall, T. (2003). Conceptualising 'Value for the Customer': An Attributional, Structural and Dispositional Analysis. Academy of Marketing Science Review, 12, 1-42. 